\title{
Promoting Work Ability With a Wearable Activity Tracker in Working Age Individuals With Hip and/or Knee Osteoarthritis: A Randomized Controlled Trial
}

Elin Östlind ( $\square$ elin.ostlind@med.lu.se )

Lund University

Frida Eek

Lund University

Kjerstin Stigmar

Lund University

Anita Sant'Anna

Viniam Consulting $A B$

Eva Ekvall Hansson

Lund University

\section{Research Article}

Keywords: Hip osteoarthritis, Knee osteoarthritis, Physical activity, Wearable activity tracker, Work ability, Mhealth

Posted Date: August 2nd, 2021

DOI: https://doi.org/10.21203/rs.3.rs-634847/v1

License: (c) (i) This work is licensed under a Creative Commons Attribution 4.0 International License. Read Full License

Version of Record: A version of this preprint was published at BMC Musculoskeletal Disorders on February 3rd, 2022. See the published version at https://doi.org/10.1186/s12891-022-05041-1. 


\section{Abstract}

Background: Physical activity (PA) can improve work ability and health in individuals with hip and/or knee osteoarthritis (OA). The use of wearable activity trackers (WATs) has been shown to increase PA and improve other health outcomes but little is known concerning their effect on work ability. The objectives in this study was to examine the effect of selfmonitoring PA with a WAT on work ability, PA and work productivity among individuals of working age with hip and/or knee OA.

Methods: Individuals ( $\mathrm{n}=160$ ) were included and cluster-randomized to a Supported Osteoarthritis Self-management Program (SOASP) with the addition of self-monitoring PA using a commercial WAT for 12 weeks $(n=86)$, or only the SOASP ( $n=74)$. Primary outcome was self-reported work ability measured with the Work Ability Index (WAI) and secondary outcomes were self-reported PA measured with the International Physical Activity Questionnaire - Short Form (IPAQ-SF) and work productivity, measured with the Work Productivity and Activity Impairment scale: Osteoarthritis (WPAl:OA) at baseline and after three, six and twelve months. Data was primarily analysed with linear mixed models.

Results: Participants with data from baseline and at least one follow-up were included in the analyses ( $n=124)$. Linear mixed models showed no statistically significant difference between groups regarding pattern of change in work ability or PA, from baseline to follow-ups.

Conclusion: The SOASP together with self-monitoring PA with a WAT did not have any effect on the primary outcome variable work ability. Participants already at baseline had good work ability and were physically active, probably thus reducing the possibility for improvements. Future interventions should target a population with lower work ability and PA-level.

Trial registration: Clinica/Trials.gov, NCT03354091. Registered 15/11/2017, https://clinicaltrials.gov/ct2/show/NCT03354091

\section{Background}

Osteoarthritis (OA) is a common musculoskeletal disorder (1) affecting both individuals and the society at large $(2,3)$. OA often leads to pain, disability and reduced quality of life $(2,4)$ which have been shown to affect work ability (5) and productivity (6) with presenteeism (reduced work capacity) being more common than absenteeism (7-9). In a large population-based cohort study conducted in Sweden, individuals with knee OA had an almost two-folded risk of sick leave and $40-50 \%$ increased risk of disability pension in comparison with the general population (10). The recommended non-surgical core treatment for management of hip and knee OA is education and exercise (11). In Sweden, a Supported Osteoarthritis Self-management Program (SOASP) is recommended as the first-line treatment of patients with OA in the hip, knee and hand $(12,13)$. The minimal intervention in the SOASP includes two theoretical group sessions presenting information about $\mathrm{OA}$, exercise and self-management.

Physical activity (PA) has been shown to reduce pain, improve physical function and health-related quality of life for individuals with lower limb OA $(14,15)$. Previous research has also reported that exercise in the workplace (16) and walking programs (17) are effective in improving work ability and reducing work place limitations in individuals with hip and/or knee OA. Moderate or vigorous PA (MVPA) for at least 150 min per week is recommended to all adults by the World Health Organization (WHO) to reduce the risk of all-cause mortality, coronary heart disease, type 2 diabetes, depression and several other diseases (18). However, a majority of individuals with hip and/or knee OA do not meet these PA recommendations (19-21). 
A popular and effective method to increase PA (particularly walking) in healthy populations (22-24) as well as in populations with OA and other chronic conditions $(25,26)$ is the utilization of wearable activity trackers (WATs). WATs are often worn on the wrist and are paired with a smartphone, tablet or computer application (app). They can be used to self-monitor PA and increase long-term PA participation (22). WATs utilize behavior change techniques (BCTs) such as goal-setting, self-monitoring and non-specific rewards that are effective in improving adherence to PA in short- and longterm (27). WATs have also been shown to have beneficial effects on other outcomes such as mobility (24) and cardiometabolic health (25). To our knowledge, there are no published studies examining the effect of WAT-usage on work ability and work productivity among individuals with hip and/or knee OA.

Thus, the primary objective in this study was to examine the effects of adding self-monitoring PA with a WAT to the SOASP on work ability and the secondary objectives PA and work productivity among individuals of working age with hip and/or knee OA compared to the SOASP only. We expected that the intervention group would improve their work ability, PA and work productivity compared to the control group.

\section{Methods}

Design

We did a two-armed cluster-randomized (C-RCT) study with allocation ratio 1:1, comparing the SOASP with the SOASP together with self-monitoring PA using a commercial WAT (Fitbit Flex 2) for 12 consecutive weeks as an add-on. The CRCT is registered in clinical trials, 15/11/2017 (No: NCT03354091) (28). After trial commencement, an additional method (Facebook) was used to recruit participants due to low recruitment rate. Participants PA-levels and adherence to using the WAT during the intervention has previously been described (29).

Participants and recruitment

Eligible for recruitment in this study were individuals of working age in southern Sweden with hip and/or knee OA. The inclusion criteria were: working $\geq 50 \%$ (20 hrs. /week), aged between 18-67 years, being able to understand Swedish in speech and writing and able to participate in PA. They also had to have access to a smartphone, tablet or computer to use the Fitbit-app and be able to wear a WAT for 12 weeks. Potential participants in this study were approached in two different ways. Physiotherapists at 28 healthcare centers and physiotherapy clinics in southern Sweden were contacted in 2017-2018 and asked to inform individuals participating in the SOASP about the research project. The physiotherapists informed the first author EÖ about planned SOASPs $(n=114)$. The healthcare centers offered SOASPS from twice yearly up to ten times yearly and each SOASP had between three to fifteen participants. Participants in the SOASPs were given oral and written information about the research project, inclusion/exclusion criteria and how to register. Interested individuals $(n=43)$ that met the criteria self-registered on the project's website using an electronic identification (ID) service (30) and thereby giving their informed consent. In 2018, a Facebook advertisement was added to recruit additional participants. Individuals that were interested registered on the project's website and took part of a SOASP offered within the research project. EÖ was responsible for the SOASPs held within this project $(n=9)$ that consisted of three theoretical sessions. An individual visit with a physiotherapist (EÖ) was also offered.

Intervention

Participants in both groups (intervention/control) took part of the SOASP, which is described more extensively elsewhere (12,13). The SOASP offers first line treatment for patients with hip, knee and/or hand OA and is generally offered in primary health care. The SOASP consists of at least two theoretical group sessions. Participants are also offered an individual appointment with a physiotherapist and introduced to specific exercises based on their needs and goals. Some healthcare centers or physiotherapy clinics offer additional group sessions with other health care 
professionals such as occupational therapists or dieticians; and supervised group training, often for a limited period, e.g. two times a week for six weeks.

The intervention in this study comprised the SOASP together with self-monitoring PA using a commercial wrist-worn WAT (Fitbit Flex 2) for 12 consecutive weeks as an add-on. The Fitbit Flex 2 continually estimates steps taken, distance traveled, and time in different activity levels. The Fitbit is waterproof and can be worn during swimming and showering. The device is worn inside a rubber wristband and has five small LED-lights but no display. The measurements are transmitted via Bluetooth from the device to a smartphone, tablet or computer app, which in turn transfers the data to the Fitbit servers. All registered activity data can be viewed anytime on the app or on the Fitbit user portal.

Each participant in the intervention arm met with EÖ and received the Fitbit. They were aided in installing the Fitbit app and synchronizing the device to the participant's app as well as connecting the participant's Fitbit account to the study via the project's website. The participants in the intervention group were asked to wear the Fitbit for 12 weeks, from morning until bedtime. They were also asked to monitor their activity by using the app once a day. Using the app once per day allowed for synchronization of the data from the device to the app. During the 12-week period, there were no planned reminders but if participants had several (4-5) days without registered activity, EÖ contacted them by e-mail to ensure that there were no technical issues.

The default activity goal of 10,000 steps per day was changed to 7,000 because we wanted it to be achievable for the participants. Previous research has also suggested that 7,000 steps per day might be an accurate estimate for meeting the recommended 150 min per week of MVPA $(31,32)$. The other default activity goals (distance, calories burned and bouted active minutes) in the app remained unchanged. Participants received a notification from the Fitbit when they reached their goals.

\section{Outcomes and measurements}

The primary outcome in this study was self-reported work ability. The secondary outcomes were self-reported PA and self-reported work productivity. All outcomes were assessed at baseline and follow-up at three, six and twelve months with an online-survey that was sent to the participants' e-mail.

Work ability was measured with Work Ability Index (WAI), a self-reported instrument containing questions about health, work demands and sick leave (33). The index is calculated from seven questions and ranges from 7-49. The index from WAI can also be categorized in four different categories with a higher number indicating higher work ability; "poor" 7-27, "moderate" 28-36, "good" 37-43 and "excellent" 44-49 (34). The WAI has shown acceptable predictive validity (35) and test-retest reliability (36). Only the index value was considered in the analyses in this study.

PA was measured with the International Physical Activity Questionnaire - Short Form, (IPAQ-SF) (37). IPAQ-SF is selfreported and comprises nine questions about time spent in high intensity, moderate intensity, walking or sitting in the last seven days. The outcomes of IPAQ-SF are Metabolic Equivalent of Tasks (MET) minutes/week and PA category score (low, moderate or high). MET-minutes and PA category were calculated for each individual according to the IPAQSF protocol (38). In this study, only MET-minutes were used in the analyses.

Work Productivity was measured with the self-reported Work Productivity and Activity Impairment scale - osteoarthritis (WPAl:OA) (39). WPAl:OA yields four scores: absenteeism (work time missed), presenteeism (impairment at work/reduced on-the-job effectiveness), work productivity loss (overall work impairment/absenteeism plus presenteeism) and activity impairment (40). The scores are expressed as impairment percentages with higher numbers indicating greater impairment and less productivity.

Sample size 
A sample size calculation was made using the primary outcome variable work ability measured with WAI to determine the required number of participants with a power of $80 \%$ and a two-tailed significance level of 0.05 . Effect sizes (between group differences) for WAI were pragmatically based on SD on WAI from previous studies (5.41) with the approximation of $0.45 \mathrm{SD}$ as the minimal clinically important difference (42). The sample size calculation yielded approximately 80 participants per group.

Randomization

Each SOASP held at healthcare centers or within the project was seen as a cluster. Each cluster was randomly allocated to either control or intervention group. The recruitment period ran from October 2017 to May 2019. The participants were recruited from 116 SOASPs at healthcare centers and nine SOASPs conducted exclusively within the project. A randomization plan (1:1) was generated from randomization.com with seven blocks and 128 number of sealed envelopes. EÖ handled the randomization plan and EEH handled the sealed envelopes. EÖ received information about planned SOASPs and used the sealed envelopes to cluster-randomize the SOASPs. A total of 125 sealed envelopes were used, 63 SOASPs were randomized to control and 62 SOASPs were randomized to intervention. Neither participants nor authors were blinded after the allocation to control or intervention.

Data analysis

Statistical analyses were made using statistical package IBM SPSS Statistics version 27 (43). The proportion of participants at baseline in different categories according to WAI and IPAQ-SF are described. Descriptive outcome scores for baseline and follow-ups are were calculated as mean (SD). Due to skewed distribution and as recommended in the manual, IPAQ-SF MET-minutes were also calculated as median (IQR) (38).

A linear mixed model (44) was conducted to examine the effect of group (intervention/control) on participants' scores on the primary outcome work ability and the secondary outcomes PA and work productivity from baseline to three, six or twelve month follow-ups. Group and time were added as fixed factors. Interaction Group*Time was further added to assess the difference in pattern of change (effect) between the groups. The secondary outcome variables PA and work productivity were non-normally distributed and therefore log-transformed with lg10 prior to analysis to meet the assumptions of the linear mixed model.

Changes in the outcome measures from baseline to each follow up time was also computed, and compared between groups through Analysis of covariance (ANCOVA) with adjustment for the baseline scores (45). Mean adjusted differences and $95 \%$ confidence intervals $(\mathrm{Cl})$ were calculated. Since the change/difference scores were approximately normally distributed also for the IPAQ-SF and WPAI:OA, raw change/difference scores were included in all ANCOVA models.

Due to differences in the distribution of men and women in the groups, the analyses were also performed with sex included as a potential confounder. Adjusting for sex did not have an impact on the results and sex was hence not included in the final analyses.

\section{Results}

We included individuals ( $n=160)$ of working age with hip and/or knee OA from October 2017 until May 2019 with the last follow-up in May 2020. Participant recruitment ended when sufficient number of participants were included. A flow diagram is shown in figure 1. Twenty-one individuals dropped out due to different reasons before answering the baseline questionnaire. 
Only participants that answered the questionnaire at baseline and at least one follow-up were included in the analyses $(n=124), 103$ women and 21 men and the intention-to-treat principle was used. Participants were on average 55.8 (SD 5.7) years and a majority reported having sedentary work and being less physically active compared to before they were diagnosed with OA (table 1). Some minor differences were observed between the groups, especially regarding distribution of men and women with a higher proportion of men in the control group. Participants in the control group that were included after August $2018(n=27)$ were asked if they had used a private WAT during the study and $37 \%$ $(n=10)$ participants answered yes. A majority of the participants in both groups reported good or excellent work ability at baseline and were categorized as being moderate or highly physically active (table 1).

Primary outcome (work ability)

The linear mixed model showed no statistically significant interaction (Group*Time) for the primary outcome work ability $(p=0.948)$. Also, there were no statistically significant main effect for group $(p=0.305)$ or time $(p=0.155)$. The ANCOVA showed no statistically significant between group differences regarding change in work ability for any of the periods (baseline to three, six or twelve month follow-up) were found (table 2).

Secondary outcomes (PA and work productivity)

Median MET-minutes at baseline were 2335 (IQR 1408-3605) minutes for the control group and 2358 (IQR 1314-5310) minutes for the control group (figure 2). The linear mixed model showed no statistically significant interaction (Group*Time) for IPAQ-SF, WPAl:OA scores absenteeism, work productivity loss and activity impairment. There were, however, a statistically significant main effect for time for WPAI:OA activity impairment, $\mathrm{p}=0.013$ and a statistically significant interaction effect (Group*Time) for WPAl:OA presenteeism, $\mathrm{p}=0.010$.

ANCOVA with adjustment for baseline values, showed no statistically significant difference between or within groups regarding change in IPAQ-SF, WPAl:OA absenteeism and WPAl:OA activity impairment, from baseline to follow-ups. There were a statistically significant difference between the groups regarding change between baseline and three month follow-up for WPAI:OA presenteeism and WPAl:OA work productivity loss but no statistically significant difference between the groups regarding change from baseline to six or twelve month follow-up (table 2).

\section{Discussion}

In this C-RCT, we examined the effect of the SOASP with the addition of self-monitoring PA with a WAT compared to the SOASP alone on work ability, PA and work productivity in individuals with hip and/or knee OA of working age. Contrary to our expectation, we did not find any effect of the intervention on the primary outcome work ability, the secondary outcome PA and only to some minor extent work productivity (absenteeism and activity impairment).

The participants in this study had on average high scores on WAl throughout the study period, with both groups having a mean score ranging from 39.2 to 41.6 , consequently falling within the "good" work ability classification on WAI (34). Both groups had a lower WAI-score at three and six month follow-up compared to baseline but the changes were small and not statistically significant. The scores on WAI in this study are comparable $(5,16)$ or higher $(41)$ than the scores reported in previous studies on working OA-populations, indicating less possibility for improving the score on WAI.

Participants were on average also highly physically active already at baseline according to IPAQ-SF with a majority of the participants in PA-categories moderate and high. The intervention group had a statistically significant increase in mean MET-minutes from baseline to three months, which might indicate an effect of the intervention, but the difference in change between the groups was not statistically significant. The already high levels of PA at baseline might have limited the potential for improvement. Lack of leisure-time vigorous PA, poor musculoskeletal capacity and high physical 
work load are among important factors associated with a poor work ability (46) but in this study, a majority of the participants were categorized as moderately or highly physically active and did not have a physically demanding work.

The results on WPAl:OA showed a very low absence from work due to OA but a larger presenteeism/impairment at work. This result is in line with the results from previous research (7-9) reporting a higher prevalence of presenteeism than absenteeism. In addition, a systematic review reported that individuals with OA experience difficulties at work and have a lower work productivity but still remain at work (47). Presenteeism/impairment at work decreased significantly from baseline to three month follow-up in the intervention group and there was a significant difference between the groups regarding change from baseline to the three month follow-up. However, this finding should be interpreted with caution since the difference did not persist throughout the remaining follow-ups.

Some limitations need to be considered. The first limitation regards selection bias. Participants self-registered to the study and a majority of them were recruited from the Facebook advertisement. This method of recruitment requires more effort from potential participants and consequently, we believe that many of the participants in this study already had an interest in e-health and were physically active. Also, using Facebook to recruit participants is a cost-effective and time saving method but leads to an over representation of young, white women (48). In comparison with a large Swedish OA-cohort (49), the participant characteristics in this study differed on several points. In our study, participants had a lower mean age and there were higher proportions of females and participants with post-secondary education compared to the large cohort (49). Some of these differences might be explained by the inclusion of only working age individuals in this study. However, we still believe that the participants in this study are probably not representative of the general population of working individuals with hip and/or knee OA. An additional limitation is also related to selection bias. Almost $40 \%$ of the participants reported already regularly using a WAT prior to taking part in this study, which supports the assumption that the participants in this study already were interested in e-health and monitoring PA. This corresponds well to the findings of a previous study reporting that WAT-use was associated with being female, below 60 years of age, having a post-secondary education and meeting PA guidelines (50). Another limitation is that some of the participants in the control group used their own WAT during the study.

Several systematic reviews with meta-analysis have established that WAT-use is effective to increase PA $(22,23,26)$ which in turn might improve cardiometabolic health and mobility $(24,25)$. In this study, we did not find any effect on the primary outcome variable work ability and only inconsistent results on the secondary outcome variables. In a previous study within this research project, we reported objective PA-data from the Fitbits worn by the intervention group in this RCT. In short, the participants had a high PA-level throughout the intervention, walking on average more than 10000 steps per day and spending more than 300 minutes in MVPA/week (29) which further strengthens our beliefs that the participants in this study already were highly physically active. They also had good work ability, low absenteeism and relatively low presenteeism, which leaves little room for improvement. We believe that the intervention in this study might have been more effective in a population with lower work ability, PA-level and work productivity. Future research should target individuals with hip and/or knee OA with low work ability and low PA-levels to examine if WAT-use could have an effect on work ability and other health outcomes in this population.

\section{Conclusions}

The results in this C-RCT showed that the intervention comprised of the addition of self-monitoring PA with a WAT to the SOASP did not have any effect on the primary outcome work ability compared to the SOASP alone. The participants had already at baseline good work ability and were physically active which probably reduced the possibility for improvements. Future research should target a population with low work ability and low PA-level.

\section{List Of Abbreviations}




\begin{tabular}{|c|c|}
\hline $\mathrm{OA}$ & Osteoarthritis \\
\hline SOASP & Supported Osteoarthritis Self-management Program \\
\hline PA & Physical activity \\
\hline MVPA & Moderate and vigorous physical activity \\
\hline WHO & World Health Organization \\
\hline WAT & Wearable activity tracker \\
\hline App & Application \\
\hline BCT & Behavior change techniques \\
\hline C-RCT & Cluster-randomized controlled trial \\
\hline EÖ & Elin Östlind \\
\hline WAI & Work Ability Index \\
\hline IPAQ-SF & International Physical Activity Questionnaire - Short Form \\
\hline WPAI:OA & Work Productivity and Activity Index:Osteoarthritis \\
\hline MET & Metabolic Equivalent of Task \\
\hline SD & Standard deviation \\
\hline IQR & Interquartile range \\
\hline ANCOVA & Analysis of covariance \\
\hline
\end{tabular}

\section{Declarations}

Ethics approval and consent to participate

The methods in this study were performed in accordance with the WMA declaration of Helsinki (51). This study was approved by the Regional Ethical Review Board in Lund, Sweden, (2017/596). All participants received written information about the study and provided their informed consent with an electronic identification service before registering

\section{Consent for publication}

Not applicable

\section{Avaliability of data and materials}

The datasets used and analysed during the current study are available from the corresponding author on reasonable request. 


\section{Competing interests}

The authors declare that they have no competing interests.

\section{Funding}

This study received fundings from the Swedish Research Council. The funder did not take part in designing the study, collecting data, analysing, interpreting the results or writing the manuscript.

\section{Authors' contributions}

All authors (EÖ, FE, KS, AS, EEH) contributed in conceptualizing and designing the study. EÖ recruited participants, managed the intervention, handled the Fitbits and sent out questionnaires. All authors (EÖ, FE, KS, AS, EEH) contributed in analysing and writing the manuscript and all authors read and approved the final manuscript.

\section{Acknowledgements}

We would like to thank the participants in this study.

\section{References}

1. Murray CJL, Vos T, Lozano R, Naghavi M, Flaxman AD, Michaud C, et al. Disability-adjusted life years (DALYs) for 291 diseases and injuries in 21 regions, 1990-2010: a systematic analysis for the Global Burden of Disease Study 2010. The Lancet. 2012 Dec 15;380(9859):2197-223.

2. Hunter DJ, Schofield D, Callander E. The individual and socioeconomic impact of osteoarthritis. Nat Rev Rheumatol. 2014 Jul;10(7):437-41.

3. GBD 2017 DALYs and HALE Collaborators. Global, regional, and national disability-adjusted life-years (DALYs) for 359 diseases and injuries and healthy life expectancy (HALE) for 195 countries and territories, 1990-2017: a systematic analysis for the Global Burden of Disease Study 2017. Lancet Lond Engl. 2018 Nov 10;392(10159):1859922.

4. Hawker GA, Stewart L, French MR, Cibere J, Jordan JM, March L, et al. Understanding the pain experience in hip and knee osteoarthritis-an OARSI/OMERACT initiative. Osteoarthritis Cartilage. 2008 Apr;16(4):415-22.

5. Xiang L, Low AHL, Leung YY, Fong W, Gan WH, Graves N, et al. Work disability in rheumatic diseases: Baseline results from an inception cohort. Int J Rheum Dis. 2020 Aug;23(8):1040-9.

6. Stewart WF, Ricci JA, Chee E, Morganstein D, Lipton R. Lost productive time and cost due to common pain conditions in the US workforce. JAMA. 2003 Nov 12;290(18):2443-54.

7. Kingsbury SR, Gross HJ, Isherwood G, Conaghan PG. Osteoarthritis in Europe: impact on health status, work productivity and use of pharmacotherapies in five European countries. Rheumatol Oxf. 2014 May;53(5):937-47.

8. Nakata K, Tsuji T, Vietri J, Jaffe DH. Work impairment, osteoarthritis, and health-related quality of life among employees in Japan. Health Qual Life Outcomes. 2018 Apr 17;16(1):64. 
9. Agaliotis M, Fransen M, Bridgett L, Nairn L, Votrubec M, Jan S, et al. Risk factors associated with reduced work productivity among people with chronic knee pain. Osteoarthritis Cartilage. 2013 Sep;21(9):1160-9.

10. Hubertsson J, Petersson IF, Thorstensson CA, Englund M. Risk of sick leave and disability pension in workingage women and men with knee osteoarthritis. Ann Rheum Dis. 2013 Mar;72(3):401-5.

11. Bannuru RR, Osani MC, Vaysbrot EE, Arden NK, Bennell K, Bierma-Zeinstra SMA, et al. OARSI guidelines for the non-surgical management of knee, hip, and polyarticular osteoarthritis. Osteoarthritis Cartilage. 2019 Nov;27(11):157889.

12. Thorstensson CA, Garellick G, Rystedt H, Dahlberg LE. Better Management of Patients with Osteoarthritis: Development and Nationwide Implementation of an Evidence-Based Supported Osteoarthritis Self-Management Programme. Musculoskeletal Care. 2015 Jun;13(2):67-75.

13. Jönsson T, Eek F, Dell'Isola A, Dahlberg LE, Ekvall Hansson E. The Better Management of Patients with Osteoarthritis Program: Outcomes after evidence-based education and exercise delivered nationwide in Sweden. PloS One. 2019;14(9):e0222657-e0222657.

14. Kraus VB, Sprow K, Powell KE, Buchner D, Bloodgood B, Piercy K, et al. Effects of Physical Activity in Knee and Hip Osteoarthritis: A Systematic Umbrella Review. Med Sci Sports Exerc. 2019 Jun;51(6):1324-39.

15. Sharma L, Cahue S, Song J, Hayes K, Pai Y-C, Dunlop D. Physical functioning over three years in knee osteoarthritis: role of psychosocial, local mechanical, and neuromuscular factors. Arthritis Rheum. 2003 Dec;48(12):3359-70.

16. Chopp-Hurley JN, Brenneman EC, Wiebenga EG, Bulbrook B, Keir PJ, Maly MR. Randomized Controlled Trial Investigating the Role of Exercise in the Workplace to Improve Work Ability, Performance, and Patient-Reported Symptoms Among Older Workers With Osteoarthritis. J Occup Environ Med. 2017;59(6):550-6.

17. Nyrop KA, Charnock BL, Martin KR, Lias J, Altpeter M, Callahan LF. Effect of a six-week walking program on work place activity limitations among adults with arthritis. Arthritis Care Res. 2011 Dec;63(12):1773-6.

18. WHO | Information sheet: global recommendations on physical activity for health 18 - 64 years old [Internet]. [cited 2021 Jun 4]. Available from:

https://www.who.int/dietphysicalactivity/publications/recommendations18_64yearsold/en/

19. Thoma LM, Dunlop D, Song J, Lee J, Tudor-Locke C, Aguiar EJ, et al. Are Older Adults With Symptomatic Knee Osteoarthritis Less Active Than the General Population? Analysis From the Osteoarthritis Initiative and the National Health and Nutrition Examination Survey. Arthritis Care Res. 2018;70(10):1448-54.

20. Chang AH, Song J, Lee J, Chang RW, Semanik PA, Dunlop DD. Proportion and associated factors of meeting the 2018 Physical Activity Guidelines for Americans in adults with or at risk for knee osteoarthritis. Osteoarthritis Cartilage. 2020 Mar 18;

21. Kim IJ, Kim HA, Seo YI, Jung YO, Song YW, Jeong JY, et al. Prevalence of knee pain and its influence on quality of life and physical function in the Korean elderly population: a community based cross-sectional study. J Korean Med Sci. 2011 Sep;26(9):1140-6.

22. Brickwood K-J, Watson G, O’Brien J, Williams AD. Consumer-Based Wearable Activity Trackers Increase Physical Activity Participation: Systematic Review and Meta-Analysis. JMIR MHealth UHealth. 2019;7(4):e11819. 
23. Laranjo L, Ding D, Heleno B, Kocaballi B, Quiroz JC, Tong HL, et al. Do smartphone applications and activity trackers increase physical activity in adults? Systematic review, meta-analysis and metaregression. Br J Sports Med. 2020 Dec 21;

24. S. Oliveira J, Sherrington C, R. Y. Zheng E, Franco MR, Tiedemann A. Effect of interventions using physical activity trackers on physical activity in people aged 60 years and over: a systematic review and meta-analysis. $\mathrm{Br} \mathrm{J}$ Sports Med. 2020 Oct;54(20):1188-94.

25. Franssen WMA, Franssen GHLM, Spaas J, Solmi F, Eijnde BO. Can consumer wearable activity tracker-based interventions improve physical activity and cardiometabolic health in patients with chronic diseases? A systematic review and meta-analysis of randomised controlled trials. Int J Behav Nutr Phys Act. 2020 May 11;17(1):57.

26. Davergne T, Pallot A, Dechartres A, Fautrel B, Gossec L. Use of Wearable Activity Trackers to Improve Physical Activity Behavior in Patients With Rheumatic and Musculoskeletal Diseases: A Systematic Review and Meta-Analysis. Arthritis Care Res Hoboken. 2019 Jun;71(6):758-67.

27. Willett M, Duda J, Fenton S, Gautrey C, Greig C, Rushton A. Effectiveness of behaviour change techniques in physiotherapy interventions to promote physical activity adherence in lower limb osteoarthritis patients: A systematic review. PloS One. 2019;14(7):e0219482.

28. Active@Work - Optimizing Physical Activity at Work. - Full Text View - ClinicalTrials.gov [Internet]. [cited 2021 Jun 4]. Available from: https://clinicaltrials.gov/ct2/show/NCT03354091

29. Östlind E, Sant'Anna A, Eek F, Stigmar K, Ekvall Hansson E. Physical activity patterns, adherence to using a wearable activity tracker during a 12-week period and correlation between self-reported function and physical activity in working age individuals with hip and/or knee osteoarthritis. BMC Musculoskelet Disord. 2021 May 15;22(1):450.

30. BankID [Internet]. [cited 2021 Jun 4]. Available from: https://www.bankid.com/en/

31. Tudor-Locke C, Craig CL, Brown WJ, Clemes SA, De Cocker K, Giles-Corti B, et al. How many steps/day are enough? For adults. Int J Behav Nutr Phys Act. 2011 Jul 28;8:79.

32. Wallis JA, Webster KE, Levinger P, Taylor NF. What proportion of people with hip and knee osteoarthritis meet physical activity guidelines? A systematic review and meta-analysis. Osteoarthritis Cartilage. 2013 Nov;21(11):164859.

33. IImarinen J. The Work Ability Index (WAI). Occup Med. 2007 Mar 1;57(2):160-160.

34. Tuomi K. Work ability index. Helsinki: Institut of Occupational Health; 1998.

35. Lundin A, Leijon O, Vaez M, Hallgren M, Torgen M. Predictive validity of the Work Ability Index and its individual items in the general population. Scand J Public Health. 2017 Jun;45(4):350-6.

36. de Zwart BCH, Frings-Dresen MHW, van Duivenbooden JC. Test-retest reliability of the Work Ability Index questionnaire. Occup Med Oxf Engl. 2002 Jun;52(4):177-81.

37. Craig CL, Marshall AL, Sjostrom M, Bauman AE, Booth ML, Ainsworth BE, et al. International physical activity questionnaire: 12-country reliability and validity. Med Sci Sports Exerc. 2003 Aug;35(8):1381-95.

38. The IPAQ group. IPAQ scoring protocol [Internet]. [cited 2021 Jun 4]. Available from: https://docs.google.com/viewer? 
$\mathrm{a}=\mathrm{v} \&$ pid=sites\&srcid=ZGVmYXVsdGRvbWFpbnx0aGVpcGFxfGd40jE0NDgxMDk3NDU1YWRIZTM

39. Reilly MC, Zbrozek AS, Dukes EM. The Validity and Reproducibility of a Work Productivity and Activity Impairment Instrument. PharmacoEconomics. 1993 Nov 1;4(5):353-65.

40. Reilly associates. WPAI General Information [Internet]. [cited 2021 Jun 4]. Available from: http://www.reillyassociates.net/WPAI_General.html

41. Lastowiecka E, Bugajska J, Najmiec A, Rell-Bakalarska M, Bownik I, Jedryka-Goral A. Occupational work and quality of life in osteoarthritis patients. Rheumatol Int. 2006 Dec;27(2):131-9.

42. Norman GR, Sloan JA, Wyrwich KW. Interpretation of Changes in Health-Related Quality of Life: The Remarkable Universality of Half a Standard Deviation. Med Care. 2003;41(5):582-92.

43. IBM Corp. Released 2020. IBM SPSS Statistics for Windows, Version 27.0. Armonk, NY: IBM Corp [Internet]. 2020 [cited 2021 Jun 4]. Available from: https://www.ibm.com/products/spss-statistics

44. Ritz C. Statistical Analysis of Continuous Outcomes from Parallel-Arm Randomized Controlled Trials in Nutrition-a Tutorial. Eur J Clin Nutr. 2021 Jan;75(1):160-71.

45. Van Breukelen GJ. ANCOVA versus change from baseline: more power in randomized studies, more bias in nonrandomized studies [corrected]. J Clin Epidemiol. 2006 Sep;59(9):920-5.

46. van den Berg TIJ, Elders LAM, de Zwart BCH, Burdorf A. The effects of work-related and individual factors on the Work Ability Index: a systematic review. Occup Environ Med. 2008 Nov 18;66(4):211-20.

47. Bieleman HJ, Bierma-Zeinstra SM, Oosterveld FG, Reneman MF, Verhagen AP, Groothoff JW. The effect of osteoarthritis of the hip or knee on work participation. J Rheumatol. 2011 Sep;38(9):1835-43.

48. Whitaker C, Stevelink S, Fear N. The Use of Facebook in Recruiting Participants for Health Research Purposes: A Systematic Review. J Med Internet Res. 2017 Aug 28;19(8):e290.

49. Dell'Isola A, Jönsson T, Ranstam J, Dahlberg LE, Ekvall Hansson E. Education, Home Exercise, and Supervised Exercise for People With Hip and Knee Osteoarthritis As Part of a Nationwide Implementation Program: Data From the Better Management of Patients With Osteoarthritis Registry. Arthritis Care Res Hoboken. 2020 Feb;72(2):201-7.

50. Macridis S, Johnston N, Johnson S, Vallance JK. Consumer physical activity tracking device ownership and use among a population-based sample of adults. PloS One. 2018;13(1):e0189298-e0189298.

51. World Medical Association. World Medical Association Declaration of Helsinki: ethical principles for medical research involving human subjects. JAMA. 2013 Nov 27;310(20):2191-4. doi: 10.1001/jama.2013.281053. PMID: 24141714.

\section{Tables}


Table 1

Participants' baseline characteristics and data (WAI and IPAQ categories) $(n=124)$

Group

$\begin{array}{ll}\text { Intervention } & \text { Control } \\ (\mathrm{n}=74) & (\mathrm{n}=50)\end{array}$

Age (years), mean (SD)

$56.7( \pm 5.3)$

$54.5( \pm 6.2)$

Sex, \% (n)

Female

87.8 (65)

76.0 (38)

Male

Married or living with partner, \% (n)

$7.2(9)$

$24.0(12)$

Children in household - yes, \% (n)

75.7 (56)

74.0 (37)

$27.0(20)$

$26.0(13)$

Most affected joint, \% (n)

Hip

$21.6(16)$

$30(15)$

Knee

$78.4(58)$

70 (35)

Education (postsecondary ), \% (n)

$67.6(50)$

$62.0(31)$

Percentage of full time employment, \% (n)

$0-25 \%$

2.7 (2)

$\mathrm{n} / \mathrm{a}$

$26-50 \%$

$6.8(5)$

$\mathrm{n} / \mathrm{a}$

$51-75 \%$

$10.8(8)$

$6.0(3)$

$76-100 \%$

78.4 (58)

$92.0(46)$

Unemployed

$1.4(1)$

$2.0(1)$

Physically demanding work, \% (n)

No

Yes, several times a week

$68.9(51)$

76.0 (38)

Yes, daily

9.5 (7)

12.0 (6)

Missing

18.9 (14)

12.0 (6)

Sedentary work, sitting $>50 \%, \%(n)$

2.7 (2)

$\mathrm{n} / \mathrm{a}$

Missing

51.4 (38)

58.0 (29)

Regula $\%$ (n)

Missing

2.7 (2)

n/a

40.5 (30)

36.0 (18)

Present physical activity level compared to before OA, \% (n)

More physically active

$2.7(2)$

$2.0(1)$

Less physically active

$10.8(8)$

$14.0(7)$

Equally physically active

$55.4(41)$

$50.0(25)$

32.4 (24)

36.0 (18) 
Missing

WAl, categorical, \% (n)

Poor (7-27 points)

Moderate (28-36)

Good (37-43)

Excellent (44-49)

Missing

IPAQ, categorical, \% (n)

Low
Moderate
High
Missing
SD Standard deviation; WAT Wearable activity tracker; OA Osteoarthritis

$1.4(1) \quad$ n/a

$4.1(3) \quad 2.0(1)$

$18.9(14) \quad 20.0(10)$

$39.2(29) \quad 26.0(13)$

$33.8(25) \quad 44.0(22)$

$4.1(3) \quad 8.0(4)$

WAI Work Ability Index; IPAQ International Physical Activity Questionnaire 
Table 2. Primary and secondary outcomes. Change within and difference between the groups from baseline to follow-ups.

\section{Intervention}

$\begin{array}{lll}n & \text { Mean } & \text { Adj.* } \\ & \text { (SD) } & \text { change } \\ & \text { from } \\ & \text { baseline } \\ & {[95 \% \text { Cl] }}\end{array}$

\section{Control}
n Mean
(SD)

Outcome
Between group differences

Adj.* $\quad p$

difference

[95\% Cl]

\section{WAI}

$\begin{array}{lccllllll}\text { Baseline } & 71 & \begin{array}{l}40.1 \\ (6.3)\end{array} & \mathrm{n} / \mathrm{a} & 46 & 41.6(6.8) & \mathrm{n} / \mathrm{a} & \mathrm{n} / \mathrm{a} & \mathrm{n} / \mathrm{a} \\ \begin{array}{l}\text { 3-month } \\ \text { follow-up }\end{array} & 70 & \begin{array}{l}39.4 \\ (7.3)\end{array} & \begin{array}{l}-0.6[-1.9, \\ 0.6]\end{array} & 45 & 41.0(6.9) & \begin{array}{l}-0.8[-2.4, \\ 0.8]\end{array} & \begin{array}{l}0.2[-1.8, \\ 2.1]\end{array} & 0.877 \\ \begin{array}{l}\text { 6-month } \\ \text { follow-up }\end{array} & 62 & \begin{array}{l}39.1 \\ (7.4)\end{array} & \begin{array}{l}-1.0[-2.1, \\ 0.2]\end{array} & 40 & 41.2(6.2) & \begin{array}{l}-1.4[-2.8, \\ 0.0]\end{array} & \begin{array}{l}0.4[-1.4, \\ 2.2]\end{array} & 0.650 \\ \begin{array}{l}\text { 12-month } \\ \text { follow-up }\end{array} & 54 & \begin{array}{l}40.1 \\ (6.4)\end{array} & \begin{array}{ll}-0.6[-1.7, \\ 0.6]\end{array} & 36 & 40.2(7.3) & \begin{array}{l}-1.0[-2.5, \\ 0.4]\end{array} & \begin{array}{l}0.5[-1.4, \\ 2.3]\end{array} & 0.618 \\ \end{array}$

\section{IPAQ-SF MET-}

minutes/week

\begin{tabular}{lclllllll} 
Baseline & 67 & $\begin{array}{l}3167 \\
(2410)\end{array}$ & $\mathrm{n} / \mathrm{a}$ & 45 & $\begin{array}{l}2654 \\
(1817)\end{array}$ & $\mathrm{n} / \mathrm{a}$ & $\mathrm{n} / \mathrm{a}$ & $\mathrm{n} / \mathrm{a}$ \\
$\begin{array}{l}\text { 3-month } \\
\text { follow-up }\end{array}$ & 64 & $\begin{array}{l}3471 \\
(2395)\end{array}$ & $\begin{array}{l}647[146, \\
1148]\end{array}$ & 41 & $\begin{array}{l}2864 \\
(1908.28)\end{array}$ & $\begin{array}{l}-95[-698, \\
509]\end{array}$ & $\begin{array}{l}741[-44, \\
1526]\end{array}$ & 0.064 \\
$\begin{array}{l}\text { 6-month } \\
\text { follow-up }\end{array}$ & 61 & $\begin{array}{l}3319 \\
(2527)\end{array}$ & $\begin{array}{l}365[-191, \\
921]\end{array}$ & 43 & $\begin{array}{l}2918 \\
(1809)\end{array}$ & $\begin{array}{l}139[-530, \\
808]\end{array}$ & $\begin{array}{l}226[-653, \\
1104]\end{array}$ & 0.611 \\
$\begin{array}{l}12-\text {-month } \\
\text { follow-up }\end{array}$ & 57 & $\begin{array}{l}2774 \\
(2114)\end{array}$ & $\begin{array}{l}-3[-511, \\
505]\end{array}$ & 37 & $\begin{array}{l}2636 \\
(1714)\end{array}$ & $\begin{array}{l}-136[-763, \\
491]\end{array}$ & $\begin{array}{l}133[-679, \\
945]\end{array}$ & 0.745 \\
\hline
\end{tabular}

\section{WPAl:OA} absenteeism

(\%)

\begin{tabular}{|c|c|c|c|c|c|c|c|c|}
\hline Baseline & 62 & $\begin{array}{l}2.4 \\
(14.1)\end{array}$ & $\mathrm{n} / \mathrm{a}$ & 44 & $0.0(0.0)$ & $\mathrm{n} / \mathrm{a}$ & $\mathrm{n} / \mathrm{a}$ & $\mathrm{n} / \mathrm{a}$ \\
\hline $\begin{array}{l}\text { 3-month } \\
\text { follow-up }\end{array}$ & 56 & $\begin{array}{l}1.2 \\
(6.9)\end{array}$ & $\begin{array}{l}-0.6[-2.3, \\
1.0]\end{array}$ & 40 & $0.3(2.2)$ & $\begin{array}{l}-1.1[-2.9, \\
0.7]\end{array}$ & $\begin{array}{l}0.5[-2.0 \\
2.9]\end{array}$ & 0.711 \\
\hline $\begin{array}{l}\text { 6-month } \\
\text { follow-up }\end{array}$ & 49 & $\begin{array}{l}3.1 \\
(12.1)\end{array}$ & $\begin{array}{l}1.1[-1.8, \\
4.0]\end{array}$ & 32 & $0.7(2.9)$ & $\begin{array}{l}-0.9[-4.4, \\
2.7]\end{array}$ & $\begin{array}{l}2.0[-2.6 \\
6.6]\end{array}$ & 0.390 \\
\hline $\begin{array}{l}\text { 12-month } \\
\text { follow-up }\end{array}$ & 52 & $\begin{array}{l}3.8 \\
(13.7)\end{array}$ & $\begin{array}{l}2.1[-1.5, \\
5.6]\end{array}$ & 33 & 1.7 (8.7) & $\begin{array}{l}0.2[-4.3 \\
4.6]\end{array}$ & $\begin{array}{l}1.9[-3.8 \\
7.6]\end{array}$ & 0.508 \\
\hline \multicolumn{9}{|c|}{$\begin{array}{l}\text { WPAl:OA } \\
\text { presenteeism } \\
(\%)\end{array}$} \\
\hline Baseline & 66 & $\begin{array}{l}19.7 \\
(25.7)\end{array}$ & $\mathrm{n} / \mathrm{a}$ & 45 & $\begin{array}{l}18.7 \\
(24.9)\end{array}$ & $\mathrm{n} / \mathrm{a}$ & $\mathrm{n} / \mathrm{a}$ & $\mathrm{n} / \mathrm{a}$ \\
\hline $\begin{array}{l}\text { 3-month } \\
\text { follow-up }\end{array}$ & 68 & $\begin{array}{l}11.8 \\
(20.2)\end{array}$ & $\begin{array}{l}-8.1[-13.1, \\
-3.1]\end{array}$ & 43 & $\begin{array}{l}19.8 \\
(28.6)\end{array}$ & $\begin{array}{l}3.1[-3.1 \\
9.4]\end{array}$ & $\begin{array}{l}-11.3[-19.3, \\
-3.2]\end{array}$ & 0.006 \\
\hline
\end{tabular}




\begin{tabular}{lclllllll}
$\begin{array}{l}\text { 6-month } \\
\text { follow-up }\end{array}$ & 55 & $\begin{array}{l}16.5 \\
(24.6)\end{array}$ & $\begin{array}{l}-2.8[-8.8, \\
3.2]\end{array}$ & 41 & $\begin{array}{l}13.9 \\
(22.9)\end{array}$ & $\begin{array}{l}-3.2[-10.1, \\
3.7)\end{array}$ & $\begin{array}{l}0.4[-8.7, \\
9.5]\end{array}$ & 0.934 \\
\hline $\begin{array}{l}\text { 12-month } \\
\text { follow-up }\end{array}$ & 53 & $\begin{array}{l}14.2 \\
\text { (20.8) }\end{array}$ & $\begin{array}{l}-0.5[-5.8, \\
4.9]\end{array}$ & 37 & $\begin{array}{l}18.9 \\
(25.4)\end{array}$ & $\begin{array}{l}4.2[-2.3, \\
10.7]\end{array}$ & $-4.6[-13.1$, & 0.277 \\
\hline
\end{tabular}

\section{WPAl:OA work productivity loss \\ (\%)}

\begin{tabular}{lclllllll} 
Baseline & 61 & $\begin{array}{l}18.6 \\
(24.9)\end{array}$ & $\mathrm{n} / \mathrm{a}$ & 44 & $\begin{array}{l}18.0 \\
(24.7)\end{array}$ & $\mathrm{n} / \mathrm{a}$ & $\mathrm{n} / \mathrm{a}$ & $\mathrm{n} / \mathrm{a}$ \\
$\begin{array}{l}\text { 3-month } \\
\text { follow-up }\end{array}$ & 56 & $\begin{array}{l}15.0 \\
(22.5)\end{array}$ & $\begin{array}{l}-6.1[-12.1, \\
-0.2]\end{array}$ & 40 & $\begin{array}{l}18.9 \\
(26.5)\end{array}$ & $\begin{array}{l}3.2[-3.5, \\
9.9]\end{array}$ & $\begin{array}{l}-9.3[-18.3, \\
-0.4]\end{array}$ & 0.042 \\
$\begin{array}{l}\text { 6-month } \\
\text { follow-up }\end{array}$ & 49 & $\begin{array}{l}19.5 \\
(26.9)\end{array}$ & $\begin{array}{l}0.4[-5.8, \\
6.7]\end{array}$ & 32 & $\begin{array}{l}12.6 \\
(19.9)\end{array}$ & $\begin{array}{l}0.1[-7.6, \\
7.8]\end{array}$ & $\begin{array}{l}0.3[-9.7, \\
10.3]\end{array}$ & 0.947 \\
$\begin{array}{l}\text { 12-month } \\
\text { follow-up }\end{array}$ & 52 & $\begin{array}{l}16.3 \\
(24.8)\end{array}$ & $\begin{array}{l}2.1[-2.9, \\
7.2]\end{array}$ & 32 & $\begin{array}{l}18.8 \\
(23.6)\end{array}$ & $\begin{array}{l}5.0[-1.3, \\
11.3]\end{array}$ & $-2.9[-10.9$, & 0.481 \\
\hline
\end{tabular}

\section{WPAI-OA \\ activity \\ impairment \\ (\%)}

\begin{tabular}{|c|c|c|c|c|c|c|c|c|}
\hline Baseline & 74 & $\begin{array}{l}30.9 \\
(24.7)\end{array}$ & $\mathrm{n} / \mathrm{a}$ & 50 & $\begin{array}{l}28.8 \\
(23.4)\end{array}$ & $\mathrm{n} / \mathrm{a}$ & $\mathrm{n} / \mathrm{a}$ & $\mathrm{n} / \mathrm{a}$ \\
\hline $\begin{array}{l}\text { 3-month } \\
\text { follow-up }\end{array}$ & 71 & $\begin{array}{l}26.6 \\
(27.0)\end{array}$ & $\begin{array}{l}-4.4[-9.5, \\
0.7]\end{array}$ & 46 & $\begin{array}{l}26.1 \\
(25.9)\end{array}$ & $\begin{array}{l}-3.7[-10.0, \\
2.7]\end{array}$ & $\begin{array}{l}-0.7[-8.8 \\
7.5]\end{array}$ & 0.868 \\
\hline $\begin{array}{l}\text { 6-month } \\
\text { follow-up }\end{array}$ & 61 & $\begin{array}{l}35.6 \\
(31.4)\end{array}$ & $\begin{array}{l}5.9[-0.7 \\
12.4]\end{array}$ & 43 & $\begin{array}{l}25.1 \\
(25.4)\end{array}$ & $\begin{array}{l}-3.0[-10.8, \\
4.8]\end{array}$ & $\begin{array}{l}8.8[-1.4 \\
19.0]\end{array}$ & 0.089 \\
\hline $\begin{array}{l}\text { 12-month } \\
\text { follow-up }\end{array}$ & 60 & $\begin{array}{l}29.0 \\
(29.4)\end{array}$ & $\begin{array}{l}0.7[-4.9, \\
6.3]\end{array}$ & 38 & $\begin{array}{l}22.9 \\
(21.0)\end{array}$ & $\begin{array}{l}-3.3[-10.3, \\
3.8]\end{array}$ & $\begin{array}{l}4.0[-5.0 \\
13.0]\end{array}$ & 0.382 \\
\hline
\end{tabular}

Analysis of Covariance (ANCOVA) were performed to analyze change within and difference between the groups.

*Adjusted for baseline values.

SD: standard deviation; Cl: confidence interval; WAl: Work Ability Index; IPAQ-SF: International Physical Activity Questionnaire - Short Form; MET: Metabolic Equivalent of Task

WPAI:OA: Work Productivity and Activity Impairment scale: Osteoarthritis

\section{Figures}




\section{Enrollment}

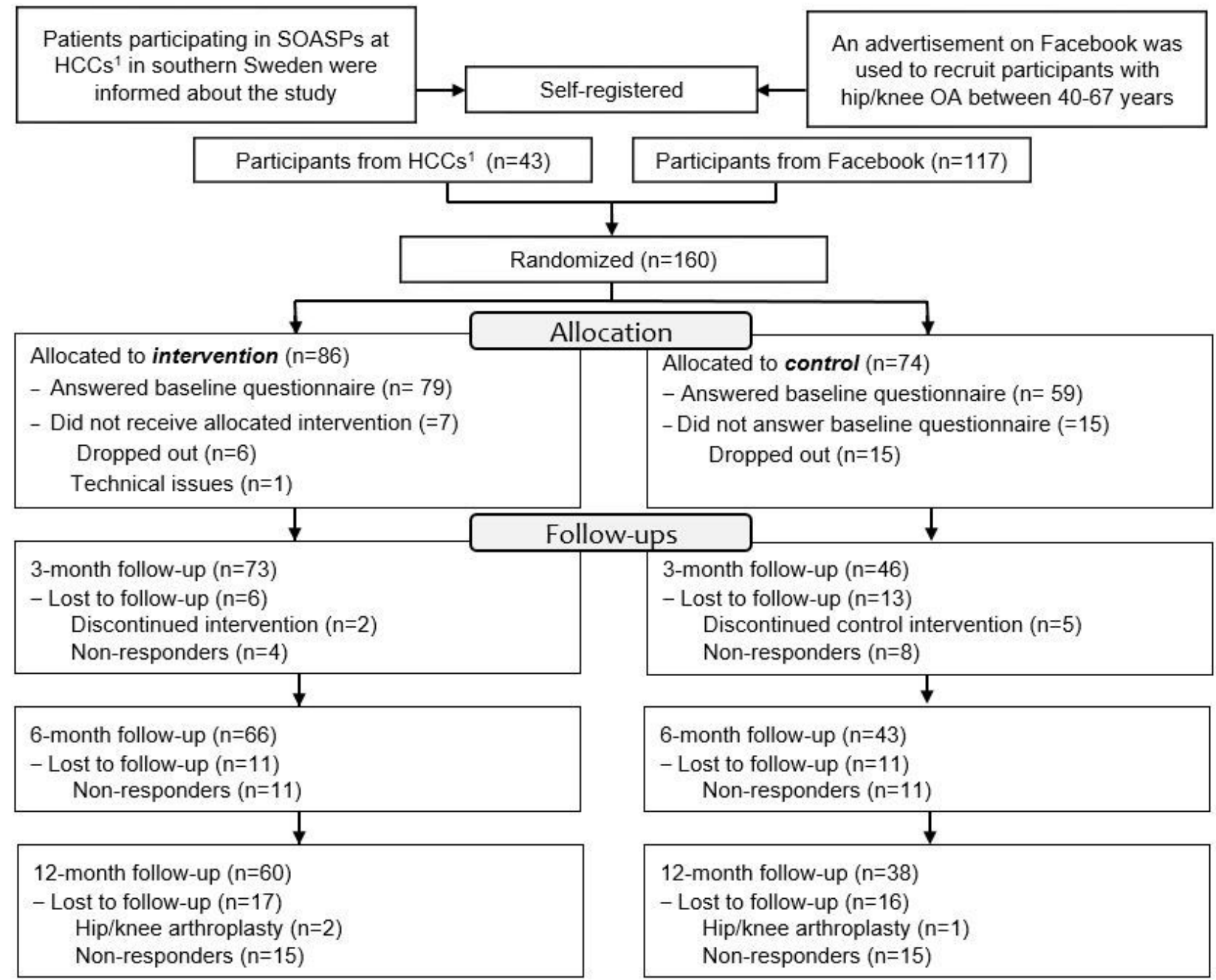

${ }^{1}$ Health care centers

\section{Figure 1}

Flow of participants and the process of the study. 


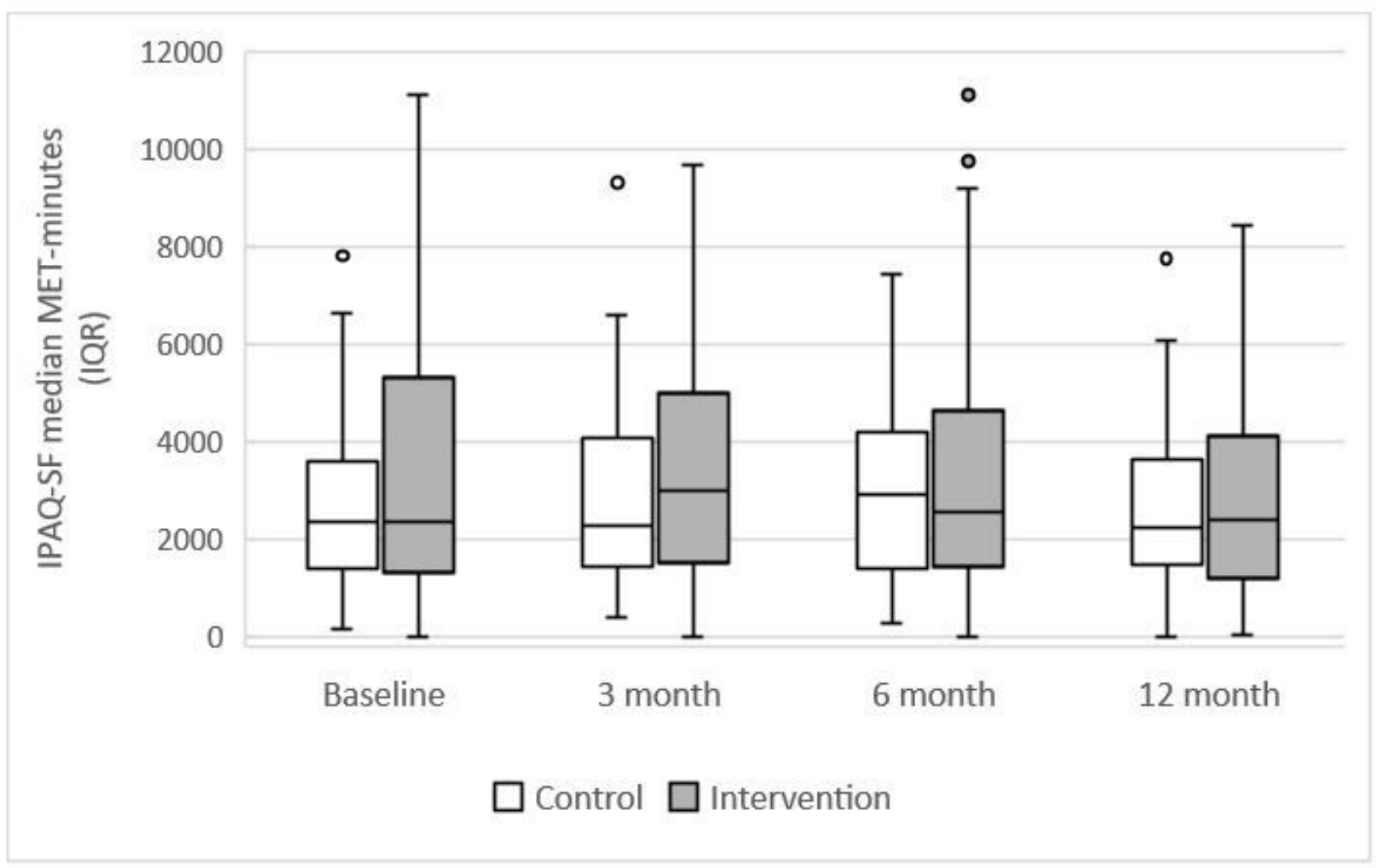

Figure 2

Median Metabolic Equivalent of Task (MET)-minutes based on International Physical Activity Questionnaire - Short Form (IPAQ-SF) for each group and measurement including interquartile range (IQR) and minimum-maximum range. The dots represent outliers. 